\title{
RESEÑA
}

\section{RECENSIÓN DE LIBRO}

Herrán, Agustín de la \& Paredes, Joaquín (2012). Promover el cambio pedagógico en la universidad. Madrid: Pirámide. 411 pp.

\author{
Luis R. Antonio Manzanares López* \\ Facultad de Teología Pontificia y Civil de Lima, Perú
}

La obra, que tiene como coordinadores a los docentes universitarios Agustín de la Herrán y Joaquín Paredes, de la Universidad Autónoma de Madrid, es el fruto del trabajo colectivo que firma un equipo de destacados profesores investigadores de reconocido prestigio, pertenecientes a diversas universidades de España, estudio en el que exponen sus conocimientos, sus reflexiones $\mathrm{y}$ sus experiencias sobre un tema que, a decir del prologuista del libro, es una cuestión decisiva para el futuro de la universidad: el cambio pedagógico.

Desde la visión de los autores, los cambios se pueden viabilizar más y pueden ser realmente profundos y exitosos, si son impulsados no desde arriba, desde las altas esferas administrativas universitarias -que deben apoyarlos o estimularlos y favorecerlos, pero no dirigirlos-, sino desde abajo, desde la gestión de los procesos de la universidad, desde el aula, desde el trabajo docente y de investigación del grupo de innovación, desde los departamentos y facultades.

En las cinco partes en las que está dividida, la obrasedirigea todoslosque están involucrados con la comunidad universitaria y les propone razones fundadas para promover cambios profundos y duraderos para la transformación didáctica y organizativa de la universidad y, a la vez, sugiere las vías de acción para alcanzarlos. "La palabra cambios actúa como nexo de unión entre unas partes y otras de la obra" (p. 18). Así, después de hacer un análisis sobre la realidad actual de la universidad y sobre su misión, y de proponer acciones dirigidas al cambio y mejora, que es el tema de la primera parte, en la segunda se analizan, en tres capítulos, temas referidos a los cambios en el funcionamiento de la universidad: micropolíticas, generación de proyectos universitarios innovadores y exitosos, representación y participación de los estudiantes en la universidad.

En la tercera parte, la más amplia de la obra, se reflexiona sobre los cambios en la planificación universitaria y los temas que se ponen a consideración se desarrollan en seis capítulos: elaboración de proyectos pedagógicos compartidos en la universidad, gestión y manejo de los conflictos por razón de planes de estudios nuevos, organización de las prácticas profesionales y la inserción profesional de los egresados, gestión de la información y 
de los recursos digitales de la universidad (bibliotecas y recursos comunes), articulación de un plan universitario de acción tutorial y organización de espacios y tiempos centrados en las personas. La cuarta parte, que consta de cuatro partes, pone a consideración temas relacionados a los cambios en la evaluación, la calidad, la mejora y la humanización de la universidad: la evaluación del alumnado, la evaluación de la calidad de la docencia universitaria, la evaluación de la producción científica. En la quinta parte, que se desarrolla en un capítulo, se hace un esfuerzo de valoración e identificación de los temas en la investigación sobre el cambio pedagógico en la universidad.

De las cinco partes, destaca la cuarta, en especial el capítulo 12, que reflexiona sobre el tema de la evaluación del alumnado, asunto bastante espinoso por algunas incongruencias, deficiencias y paradojas que presenta, pero importante, y que propone algunas estrategias para mejorarlo (p. 243); y el capítulo 13, que analiza la evaluación de la docencia universitaria, "tarea compleja y necesaria para avanzar en el saber, en el pensamiento y en la pertinencia de la práctica de enseñanza, que propicia el aprendizaje formativo de los estudiantes y el dominio de las competencias pretendidas" (p. 271).

En síntesis, la obra busca acortar la brecha existente entre las políticas educativas de la administración gubernamental o estatal y el quehacer diario de los docentes universitarios en el aula.

En todo el mundo, no solo en España, el escenario de la formación pedagógica universitaria es bastante complejo. Es conveniente un cambio en muchos planos: en el social o político, en el de la gestión de la universidad, en el didáctico... La obra que se comenta, atiende esta inquietud de cambio y ayuda a lograr que esta inquietud cale y no se esfume en todos los que tienen que ver con el quehacer universitario.

(C) Los autores. Este artículo es publicado por la Revista Digital de Investigación en Docencia Universitaria del Área de Investigación de la Dirección de Calidad Educativa, Universidad Peruana de Ciencias Aplicadas. Este es un artículo de acceso abierto, distribuido bajo los términos dela Licencia Creative Commons Atribución-CompartirIgual4.0 Internacional.(http://creativecommons.org/licenses/by-sa/4.0/), que permite el uso no comercial, distribución y reproducción en cualquier medio, siempre que la obra original sea debidamente citada. 